\title{
O universo feminino nas obras de Jane Austen
}

Adriana Sales Zardini / UFMG / JASBRA - Jane Austen Sociedade do Brasil

\begin{abstract}
RESUMO
Na sociedade inglesa do século 19, o papel da mulher era relegado ao plano da família e à possibilidade de um casamento vantajoso, com a possibilidade de se alcançar a segurança e a estabilidade financeira. Entretanto, Austen focaliza a importância da mulher no seio familiar, do casamento, das relações sociais e do papel da mulher na sociedade. Também será discutida a questão do feminismo na obra de Austen.
\end{abstract}

\section{PALAVRAS-CHAVE}

Sociedade inglesa do século 19, mulher na literatura, Jane Austen

\section{INTRODUÇÃO}

Entre as escritoras inglesas do século 19, Jane Austen pode ser considerada uma portavoz do universo feminino dessa época. Talvez pelo fato de que a própria Jane e sua irmã Cassandra não terem se casado, é compreensível que a autora acreditasse que as jovens moças precisassem de uma voz feminina na literatura. Entre os seus seis livros principais, podemos perceber como Austen retratou a vulnerabilidade de jovens tendo que viver sob as regras e responsabilidades em nome do bom nome de suas famílias e suas próprias reputações. Através das situações vividas por suas heroínas - algumas ridículas, engraçadas, desafiadoras e outras dignas de pena -, o universo feminino do século 19 é apresentado de maneira clara e, de modo geral, representa a universalidade da experiência humana. ${ }^{1}$ Motivo pelo qual suas obras são apreciadas até hoje, 200 anos após a publicação de seu primeiro livro: Razão e sensibilidade (1811).

\footnotetext{
${ }^{1}$ JANE AUSTEN'S HOUSE MUSEUM. The manners and customs of life in Jane Austen's time - or how to win the mating game.
} 
O objetivo deste artigo é mostrar como Jane Austen representa as mulheres de sua época através de suas personagens, das situações do dia a dia, das experiências familiares e em sociedade, abrangendo também a questão da posição social, da situação financeira e do casamento. Por fim, serão discutidas as tendências feministas na obra de Austen.

\section{A MULHER E A FAMÍLIA}

Na época de Austen havia uma concepção generalizada de que homens e mulheres possuíam capacidades naturais bastante diferenciadas e por esse motivo não havia igualdade entre os sexos, principalmente em relação à educação, negócios e postura perante a sociedade. A família da escritora pertencia à classe denominada gentry (classe média ou baixa aristocracia), com uma renda anual de cerca de 300 libras. $^{2}$ Além desses rendimentos, a família Austen precisava de outros recursos provenientes da escola que o patriarca Rev. George Austen (1731-1805) mantinha em sua casa. Apesar disso, o pai de Austen teve certas dificuldades financeiras que o impossibilitou de deixar recursos para suas filhas sobreviverem no futuro, deixando-as à mercê da ajuda dos irmãos. Se uma moça perdesse o pai ou o apoio financeiro de seus familiares, a saída mais digna seria ganhar dinheiro como governanta, professora de escola, companhia de damas, criada ou escritora. Um exemplo disso pode ser observado em Emma (1815), na qual a personagem Jane Fairfax, que precisa se sustentar, diz: "há agências de anúncios e que, recorrendo a elas, não teria dúvidas de encontrar em breve algo que me conviesse.”

No seio familiar as moças tinham a função de serem submissas, modestas, puras e educadas, e as qualidades exigidas concentravam-se nos estudos e talentos. Com a expansão das escolas públicas, no século 18, os meninos podiam receber a educação, de acordo com a disponibilidade financeira da família. Frequentar uma universidade era impossível para as moças, já que o acesso à faculdade não lhes era permitido e não era comum meninas e moças frequentarem escolas regulares. Somente no final da década de 1840 as faculdades Queen’s e Bedford, ligadas à Universidade de Londres, ofereceram vagas para moças, e, entre as décadas de 1860 e 1870, Oxford e Cambridge ofereceram vagas para o sexo feminino. Antes disso, as próprias famílias se encarregavam do ensino, quando possuíam uma vasta biblioteca e uma governanta. Jane e sua irmã chegaram a frenquentar a escola em dois períodos diferentes - em 1783 elas foram educadas por Mrs. Cawley, mas permaneceram lá pouco

\footnotetext{
${ }^{2}$ MCMASTER. Class.

${ }^{3}$ AUSTEN. Emma, p. 227.
} 
tempo, pois tiveram problemas de saúde; depois foram para um internato em Reading, entre 1785 e 1787. Nas obras de Austen, é possível citar alguns exemplos de crianças educadas em casa, como as crianças da família Morland (A Abadia de Northanger, 1818) e Emma, que foi educada pela governanta Miss Taylor (Emma).

A família era a base de sustentação de todas as moças pertencentes à classe média e à aristocracia daquela época; por isso, era de se esperar que os pais as deixassem certa quantia após sua morte ou que os irmãos ficassem com a responsabilidade de ajudá-las, caso não se casassem. A herança e bem materiais eram transmitidos sempre ao filho primogênito ou parente mais próximo do sexo masculino, impedindo assim que as filhas recebessem a herança. Na verdade, esse era o sistema legal da época, criado para que a fortuna ficasse sempre em nome da família por várias gerações, e para que não fosse partilhada, caso o pai decidisse dividir as terras e bens entre todos os filhos, incluindo filhas. É possível perceber a questão da primogenitura ${ }^{4}$ masculina em todos os livros de Austen, com exceção de Miss Emma Woodhouse (Emma), que recebeu direitos de herança do pai. Em Razão $e$ sensibilidade, observamos as dificuldades que passaram as irmãs Dahswood após a morte do pai, já que o irmão (por parte de pai) se recusa a ajudá-las e mantê-las no mesmo nível de vida enquanto o pai era vivo. Um exemplo é o caso de Mr. Collins, em Orgulho e preconceito (1813), que não tem filhos para receberem herança, sendo o herdeiro o parente do sexo masculino mais próximo. Nesse caso, após a morte do patriarca era uma consequênica natural as irmãs Bennet (Orgulho e preconceito) saírem da casa dos pais para que o primo a ocupasse, e é também por esse motivo que a mãe das moças se preocupa tanto em arranjar-lhes um casamento, para que não fiquem na miséria. Outro exemplo de herança para o primogênito é o caso de Tom Bertram, que fica com toda a herança, e assim o irmão caçula se vê obrigado a seguir a carreira de religiosa.

Entre as habilidades desejáveis para um moça da época é possível destacar: línguas, conhecimentos básicos de geografia e história, música, pintura ou desenho, bordado e dança. ${ }^{5}$ As principais línguas que as moças aprendiam eram o francês e o italiano, principalmente para que pudessem traduzir as músicas. Os conhecimentos relativos à geografia e à história forneciam um embasamento para futuras discussões a respeito de outros países. Por outro lado, ser uma boa pianista (pianoforte) atraia muita atenção, principalmente dos futuros pretendentes; assim, a moça seria capaz de entreter as visitas em sua futura casa. As

\footnotetext{
${ }^{4}$ Moody, em Marriage and the alternatives: the status of women, explica o direito de primogenitura e sucessão de bens de forma mais detalhada.

${ }^{5}$ SULLIVAN. The Jane Austen handbook - a sensible yet elegant guide to her world.
} 
habilidades relativas às artes em geral, como o desenho e pintura em aquarela, eram aspirações de todas as moças de família. Ser uma boa bordadeira era motivo de orgulho para a família da moça ou para o marido, já que seus trabalhos com a agulha poderiam ser expostos nas salas de visitas e apreciados por todos. Por fim, a dança era um elemento importantíssimo na vida de qualquer moça daquela época, visto que os bailes ofereciam a oportunidade de conhecer e conversar com outros rapazes. A maioria das moças praticava as danças ${ }^{6}$ com suas irmãs, até que fossem apresentadas à sociedade. ${ }^{7}$

Na obra de Austen temos diversos exemplos de moças "prendadas”: em Razão $e$ sensibilidade, Elinor faz desenhos, enquanto Marianne é uma excelente pianista; as irmãs Dashwood também tiveram acesso a uma vasta biblioteca do pai. Por outro lado, as irmãs Bennet, de Orgulho e preconceito, são moças que possuem diversas habilidades, entre elas, a dança. Fanny Price, de Mansfield Park (1814), é uma personagem que sabe bordar, ler, e subentende-se que saiba dançar bem, pois é apresentada à sociedade, dançando com muitos convidados de sua festa. Esses são apenas alguns exemplos, visto que em todos esses livros analisados é possível observar as habilidades das personagens, que estão sempre fazendo uso das mesmas para ocupar o tempo ou agradar às visitas.

Rapazes e moças possuíam diferentes formas de passatempos. Os jovens que não trabalhavam e pertenciam à classe média alta ou nobreza tinham como principais atividades de lazer e obrigações: caça, tiro, pesca; jogar $\operatorname{cartas}^{8}$ com os amigos; idas a jantares extravagantes, portando-se com discrição. ${ }^{9}$ Para citar alguns exemplos, em Orgulho $e$ preconceito, Mr. Bingley e Mr. Darcy saem para caçar, e em outra ocasião, Mr. Darcy oferece ao tio de Elizabeth Bennet os prazeres de uma boa pesca. Por outro lado, as moças podiam jogar cartas (incluindo apostas de pequenos valores), dançar, leituras, costurar, bordar, ${ }^{10}$ desenhar, fazer pinturas, exercitar a escrita, ter aulas de canto, tocar algum instrumento, fazer caminhadas ou passear em carruagens, visitar amigos, além de fazer compras buscando itens

\footnotetext{
${ }^{6}$ SULLIVAN. The Jane Austen handbook - a sensible yet elegant guide to her World, p. 163, destaca quatro danças típicas desse período: minuet, cotillion, quadrille, country dance e reel (dança escocesa).

${ }^{7}$ SULLIVAN. The Jane Austen handbook - a sensible yet elegant guide to her world.

${ }^{8}$ Os jogos de cartas mais comuns da época eram: Whist (versão moderna do bridge), Wingt-et-un (Vinte um ou black jack), speculation e piquet (similar ao pocker).

${ }^{9}$ JANE AUSTEN'S HOUSE MUSEUM. The World that Jane Austen.

${ }^{10}$ Para uma lista de bordados e como realizá-los veja SULLIVAN. The Jane Austen handbook - a sensible yet elegant guide to her world, p. 80-85.
} 
da moda para usarem. ${ }^{11}$ Podemos citar como exemplo as seguintes heroínas de Austen que se ocupam dessas atividades: Anne Elliot, de Persuasão (1817), que faz visitas à amiga e aos vizinhos; Catherine Morland, de A Abadia de Northanger (1817), que quando visita a cidade de Bath faz compras de diversos itens de moda, como: chapéus, vestidos e outros adereços,

A presença das irmãs e mães das personagens é também um ponto significativo na obra de Austen. Irmãs que se amam profundamente e se dão bem, são retratadas em dois livros: Elizabeth e Jane Bennet (Orgulho e preconceito) estão sempre juntas, enquanto Marianne e Elinor Dashwood (Razão e sensibilidade) se tornam mais próximas ao longo da narrativa. Em contrapartida, algumas irmãs são raramente citadas e não possuem nenhum tipo de amizade com as suas respectivas irmãs, como é o caso de Anne Elliot (A Abadia de Northanger) e Emma Woodhouse (Emma). Por outro lado, algumas personagens sofrem a influência de determinadas amizades, que podem ser consideradas como “irmãs simbólicas”. As personagens Elinor Dashwood, Catherine Morland e Fanny Price sofrem diversas consequências ao se envolverem com pessoas que não são suas amigas. Em contrapartida, Elizabeth Bennet, Emma Woodhouse, Anne Elliot e Catherine Morland são recompensadas por amigas que são como irmãs.

Em relação às mães das heroínas, apesar de elas terem influências sobre a vida de suas filhas, não representam papel fundamental no desenvolvimento da história de alguns livros como Emma e A Abadia de Northanger, pois estão distantes ou mortas. Porém, é a presença ineficaz ou imprópria de determinadas mães é que conduz o desenrolar das histórias, como Mrs. Bennet (Orgulho e preconceito), Mrs. Morland (A Abadia de Northanger), entre outros.

\section{A MULHER NA SOCIEDADE}

Para se viver em sociedade, as moças do século 19 tinham que seguir muitas regras de conduta, de etiqueta e padrões de moral. A maior parte da população inglesa vivia na zona rural, onde havia pouquíssimas oportunidades de as regras serem quebradas. Mesmo em Londres era praticamente impossível para qualquer pessoa não participar de eventos sociais, já que a maioria das famílias tinha hábitos parecidos quando iam às grandes cidades em determinadas épocas do ano.

No início do século 19, tanto as moças quanto os rapazes deviam obedecer às regras impostas, principalmente se o objetivo era o casamento. A primeira observação que deve ser feita é em relação aos pares: inicialmente o rapaz deveria procurar saber se havia na família

\footnotetext{
${ }^{11}$ JANE AUSTEN'S HOUSE MUSEUM. The World that Jane Austen.
} 
uma irmã mais velha que a moça à qual desejava fazer a corte. Caso isso fosse verdade, ele não poderia direcionar suas atenções à mais nova, já que a outra, a mais velha, ainda estava solteira. Sendo assim, muitas caçulas nem eram apresentadas à sociedade, isto é, não frequentavam os bailes e nem podiam se casar, até que as mais velhas não estivessem comprometidas. Como não havia telefone naquela época, era muito comum deixar cartões de visita, sempre que as pessoas quisessem retornar alguma visita ou avisar que estão em uma determinada vila ou cidade.

Em relação ao comportamento em público, era proibido para uma moça conversar com um rapaz nas ruas, praças e parques, sem que houvesse um acompanhante. Os jovens que não se conheciam deveriam ser apresentados uns aos outros pelo mestre de cerimônias do baile ou por outro conhecido. Ou seja, ninguém se apresentava diretamente à outra pessoa. Um bom exemplo dessa situação é a cena em A Abadia de Northanger, na qual Catherine se encontra com Henry Tilney: “O mestre de cerimônias lhe apresentou, como par, um rapaz muito distinto (...).”12 Até mesmo entre os homens esse costume era seguido. Mr. Darcy se espanta muito com o comportamento de Mr. Collins, que foi conversar com ele sem ao menos ter sido apresentado, demonstrando, assim, um falta de cavalheirismo.

Quanto ao vestuário, ${ }^{13}$ era importante saber se vestir, mesmo com uma renda familiar pequena. Para as moças do século 19 era preciso uma atenção especial ao modo de se vestirem. Por exemplo, elas tinham que considerar a roupa que vestiam pela manhã, feitas, em geral, de tecidos mais simples e jamais deveriam usar pérolas ou diamantes para não chamar a atenção. À noite, os vestidos eram mais elegantes e feitos com tecidos mais caros, usados principalmente em bailes e jantares. Os acessórios ${ }^{14}$ (colares, brincos, lenços, xales, chapéus, turbantes) e penteados também eram importantes e deviam ser usados com moderação. ${ }^{15}$

A posição social era delimitada pelos títulos nobiliárquicos e pela situação financeira da família da moça. As classes sociais eram divididas entre: 1) nobres (lords e ladies, duques e duquesas, marqueses, condes e condessas, viscondes e viscondessas, barões e baronesas), que recebiam os títulos por herança ou intervenção do Rei; 2) Cavalheiros e baronetes, que tinham o poder, assim como os bispos e arcebispos, de votarem na câmara dos lordes; 3)

\footnotetext{
${ }^{12}$ AUSTEN. A Abadia de Northanger, p. 18.

${ }^{13}$ Há um capítulo inteiro dedicado ao vestuário, acessórios e penteados, tanto masculino quanto feminino Um guia interessante sobre o vestuário da época de Austen pode ser encontrado em: DOWNING. Fashion in the time of Jane Austen.

${ }^{14}$ Em SULLIVAN. The Jane Austen handbook - a sensible yet elegant guide to her world, p. 91-105.

${ }^{15}$ Em 1811 foi lançado um livro sobre regras de vestuário, reeditado por R. L. Shepv em 1997.
} 
classe média, também chamada de aristocracia ou gentry; nesse nível encontram-se os proprietários de terras; 4) famílias pertencentes às profissões relacionadas ao Exército, Marinha, Direito, Medicina e Comércio (também considerados os “novos ricos”, dinheiro proveniente das transações comerciais, principalmente no exterior, como plantações de tabaco ou tráfico negreiro); 5) shabby-genteel ou "pessoas refinadas”, pessoas que receberam uma boa educação, porém não possuíam uma renda (governantas, filhas que não herdaram o dinheiro dos pais; 6) os empregados (vendedores de lojas e empregados das propriedades ${ }^{16}$ ); e 7) os pobres, que dependem das doações das classes mais abastadas.

A própria família Austen é um exemplo dessa variedade de classes sociais: o pai de Austen era Reverendo da Igreja da Inglaterra, e seus irmãos, James e Henry, também seguiram a carreira religiosa; Edward foi proprietário de terras; Francis e Charles exerceram funções na Academia Real Naval. As mulheres da família Austen tiveram destinos marcados, devido à situação financeira do pai, já que não tinham direito à parte da herança, ficando sob os cuidados dos irmãos, após a morte do patriarca.

Jane Austen utiliza uma vasta gama de exemplos da sociedade inglesa de sua época em todos os seus livros. Em graus diferentes, é possível perceber todas as classes sociais mencionadas anteriormente. Apesar de ter sido convidada a dedicar o livro Emma ao príncipe regente da Inglaterra, a autora nunca mencionou a realeza em suas obras, ou seja, a nobreza é representada pelos personagens Sir Thomas Bertram (Mansfield Park), Sir Walter Elliot (Persuasão) e Sir John Middleton (Razão e sensibilidade). Entretanto, esses personagens, com títulos de nobreza, não são muito admirados; por serem esnobes, ostentam um luxo demasiado ou tratam as pessoas de maneiras distintas. As mulheres herdavam o título apenas no nome, porém não ficavam com as heranças, como os casos de Lady Catherine de Bourgh (Orgulho e preconceito), Lady Bertram (Mansfield Park), Lady Middleton (Razão e sensibilidade) e Lady Russel (Persuasão). Entre os proprietários de terras estão: Mr. Darcy (Orgulho e preconceito) e Mr. Knightley e Mr. Woodhouse (Emma). O Exército é representado pelos personagens Coronel Brandon (Razão e sensibilidade), Wickham (Orgulho e preconceito), William Price (Mansfield Park) e Mr. Weston (Emma). Por sua vez, a Marinha é representada pelo Capitão Wentworth e pelo Almirante Croft (Persuasão). As profissões relacionadas à Igreja são representadas por diversos personagens; alguns adoráveis, como Henry Tilney (A Abadia de Northanger), Edward Ferrars (Razão e Sensibilidade) e

${ }^{16}$ SULLIVAN. The Jane Austen handbook - a sensible yet elegant guide to her world, p. 62-63 oferece uma lista com as posições dos empregados, suas respectivas funções e posições dentro do funcionamento da casa/propriedade. 
Edmund Bertram (Mansfield Park); outros enfadonhos e desestimulantes, como Mr. Collins (Orgulho e preconceito) e Mr. Elton (Emma), ou insignificantes, como Mr. Norris (Mansfield Park).

Em Emma é possível observar o microcosmo social que Austen criou com diversos exemplos das classes sociais vigentes na época. Além dos proprietários de terra e oficial do Exército, mencionados anteriormente, há o advogado John Knightley (irmão de Mr. Knightley); a solteirona Miss Bates; a aspirante a governanta Jane Fairfax; a moça que frequentou escola, mas não é filha de alguém importante, como Harriet Smith; e os pobres que Emma visita e oferece ajuda.

Ainda em relação à posição social e aos assuntos financeiros é interesse pontuar o levantamento que Copeland ${ }^{17}$ faz a respeito dos diferentes níveis de rendimentos anuais e as respectivas condições financeiras das pessoas e dos personagens de Austen. Para um estudo detalhado a sobre os empregados nessa época, o artigo de Terry ${ }^{18}$ oferece muitas informações importantes. Outro texto interessante para se conhecer um pouco mais sobre as carruagens, como eram valorizadas naquela época, e o que cada uma representava na sociedade inglesa, sugiro o texto da Jane Austen's House Museum. ${ }^{19}$

\section{A MULHER E O CASAMENTO}

De acordo com Sullivan, ${ }^{20}$ quando a mulher se casava, suas obrigações se limitavam a desenvolver uma boa relação com a empregada da casa, planejar os cardápios das refeições diárias e dos jantares, conduzir os empregados, ajudar aos mais pobres e doentes, decorar a casa, alfabetizar os filhos (se estes forem muito pequenos para terem uma governanta), entre outras responsabilidades. Sob o ponto de vista financeiro, o casamento era visto como uma tábua de salvação para as mulheres que não possuíam renda familiar e que não queriam viver na pobreza. Eram raros os casos de casamento por amor, apesar de todas as heroínas de Austen terem um final feliz com seus escolhidos, não por causa da renda do marido, mas por estarem apaixonadas.

\footnotetext{
${ }^{17}$ COPELAND. Money.

${ }^{18}$ TERRY. Seen but not heard: servants in Jane Austen's England.

${ }^{19}$ JANE AUSTEN'S HOUSE MUSEUM. The manners and customs of life in Jane Austen's time - or how to win the mating game.

${ }^{20}$ SULLIVAN. The Jane Austen handbook - a sensible yet elegant guide to her world.
} 
O casamento era um "acordo” entre as famílias. As mais abastadas tinham o interesse em aumentar ainda mais suas rendas e propriedades; já os mais pobres vislumbravam a ascensão social. Era possível para um rapaz de origem nobre se casar com a filha de um comerciante, se este possuísse uma grande fortuna e a reputação da moça fosse inquestionável. Por outro lado, se uma moça de origem nobre se interessasse por um rapaz de origem humilde, nada poderia ser feito, pois todo o dinheiro proveniente de antigas gerações poderia ficar nas mãos de comerciantes e o nome da família (nobre) se perderia. Por isso, em muitos casos, os ricos de origem nobre (old money) se consideravam melhores que as pessoas ricas, graças ao dinheiro do comércio (new money).

As leis inglesas da época colocavam a mulher em uma situação muito delicada. O direito de propriedade e o controle do dinheiro eram exclusivos dos maridos. Somente após a o The Married Woman's Property Act, ${ }^{21}$ de 1870 , é que as mulheres conquistam o direito de herdarem rendimentos e propriedades após o casamento; em 1882, conseguem manter o que conquistaram durante o casamento. Antes dessas leis, as mulheres eram tratadas como criminosas e até insanas. Por exemplo, se elas fossem vítimas de injúrias e difamações, os maridos poderiam fazer uma apelação no Tribunal exigindo ressarcimento por danos, já que eles se consideravam a única parte prejudicada da história. Se uma mulher trabalhasse após o casamento, todos os seus rendimentos pertenciam ao marido, e se desejassem o divórcio, não lhes era permitido.

O Matrimonial Causes Act, de 1857, dava ao homem o direito de se divorciar, caso a mulher lhe fosse infiel. Porém, se uma mulher pedisse o divórcio por infidelidade do marido, esta perderia a guarda dos filhos e ficava proibida de vê-los. Em Mansfield Park, Austen mostra como um casamento fracassado e a possibilidade de divórcio era algo inaceitável, principalmente para a filha de um baronete. Maria Bertram acaba fugindo com o amante e, após a descoberta da fuga, vê-se obrigada a sair da "sociedade” e viver isolada, sem contato com os familiares e sem nenhum crédito perante a sociedade. Somente em 1891 é que as mulheres conquistaram o direito do divórcio, sem restrições aos filhos. O corpo da mulher também pertencia aos maridos, que foram proibidos, nesse mesmo ano, de aprisionarem suas esposas para obterem seus direitos conjugais relativos ao sexo. Absurdamente, somente em 1991 é que as leis proibiram os maridos de estuprarem suas esposas. ${ }^{22}$

21 Uma cópia deste ato está disponível em: $<$ http://www.austlii.edu.au/au/legis/vic/hist_act/mwpa1870290/>.

${ }^{22}$ SAINT ANDREW'S UNIVERSITY. Self and Society in the Victorian Novel - women and the law in Victorian England. 
Jane Austen retrata uma variedade de casamentos em suas obras. De acordo com Moody, ${ }^{23}$ há aqueles em que a união é pouco compatível, porém bem-sucedida (Charlotte Lucas e Mr. Collins, de Orgulho e preconceito); casamentos inadequados, nos quais a mulher foi infeliz (General Tilney e sua esposa); casamentos bem-sucedidos (todas as heroínas dos seis livros principais). O fato de que todas as suas heroínas todas se casaram por amor e, no final das contas, casaram-se com bons partidos, não necessariamente reproduz a época em que Austen vivia. A própria escritora vivenciou o fato de não ter se casado, sabendo o que a esperava no futuro, já que não herdaria posses do pai: “mulheres solteiras tem uma tendência terrível para a pobreza, o que já é um forte argumento em favor do casamento.”24

Preocupadas com a velhice, algumas mulheres estavam dispostas a se casar, já que este era o único caminho para a estabilidade financeira ou até mesmo para escapar de uma família incompatível. ${ }^{25}$ Esse dilema é discutido entre as duas irmãs, Emma Watson e Elizabeth, no livro The Watsons:

Emma: - Ser tão inclinada ao casamento - perseguir um homem por causa de uma situação - é algo que me choca; não consigo entender. A probreza é um grande mal, mas para uma mulher educada e de sentimento, não pode ser dos males o pior. Eu preferiria ser professora em uma escola - e penso que nada poderia ser pior - do que me casar com um homem de quem não gosto. Elizabeth: - Eu já freqüentei a escola, Emma, eu conheço a vida que elas levam; (...) Eu não gostaria de me casar com um homem desagradável, assim como você, mas não creio que existam tantos homens desagradáveis; acredito que eu poderia gostar de qualquer homem bem humorado e com uma renda confortável. ${ }^{26}$

\section{JANE AUSTEN E O FEMINISMO}

A obra de Austen tem sido alvo de muitas críticas feministas; alguns críticos afirmam que a escritora escreveu apenas sobre jovens cujo único interesse na vida era o casamento. Entretanto, Jane foi além dessas perspectivas, escrevendo sobre as relações humanas, os problemas das mulheres de sua época, e fez até algumas críticas à sociedade inglesa. Obviamente não se pode classificá-la sob a ótica da crítica feminista, que teve suas origens no

\footnotetext{
${ }^{23}$ Moody faz uma lista mais completa de casais nas obras de Austen em MOODY. Classifications of the marriages in Jane Austen's Writings.

24 "A single woman, with a very narrow income, must be a ridiculous, disagreeable, old maid! the proper sport of boys and girls.” (AUSTEN. Emma, p. 69, tradução nossa.)

${ }^{25}$ MOODY. Marriage and the alternatives: the status of women.

${ }^{26}$ AUSTEN. Sandition and The Watsons - Austen's unfinished novels, p. 60.
} 
feminismo da década de 1960, mas sim sob a ótica dos estudos sobre o feminismo ${ }^{27}$ e da ginocrítica. ${ }^{28}$ Existem alguns estudos mais aprofundados sobre essa temática na obra de escritores como Kirkham, ${ }_{32}^{29}$ Bomarito e Hunter $^{30}$ e Looser. ${ }^{31}$

Moody salienta não ser difícil encontrar tendências feministas na obra de Austen. Em Orgulho e preconceito, Austen descreve uma fria e objetiva visão das limitadas opções das mulheres em relação ao casamento, centradas na personagem Charlotte Lucas. Além disso, a escritora demonstra sua opinião clara de que as mulheres devem ser levadas a sério, não somente por serem bonitas e elegantes, como protesta Elizabeth Bennet: “(...) não me considere uma mulher eleganteque tem a intenção de atormentá-lo, mas uma criatura racional, falando a verdade do coração.” Mesmo Fanny Price (Mansfield Park), que vive na casa dos tios, se recusa a casar-se com Henry Crawford apenas porque ele tem uma boa fortuna. Segundo Kirkham, a descrição da personagem é realizada de forma irônica, justamente para excitar a paixão sexual dos homens:

A aparente inocência e religiosidade de Fanny é um aspecto de sua sexualidade, um verniz angelical que faz com que ela seja sexualmente interesse para homens como Crawford, que desejam encontrar em suas esposas tais “virtudes”vulneráveis, bem como excitar tanto a paixão carnal quanto a proteção masculina.

É interessante destacar que os protestos feministas mais explícitos, nos seis livros principais analisados, estão relacionados à literatura. ${ }^{36}$ Alguns exemplos podem ser citados em Persuasão, quando Anne Elliot discute com o Capitão Harville a respeito de quem ama por mais tempo, o homem ou a mulher. Harville afirma: “não creio ter aberto um único livro em minha vida que não falasse da inconstância feminina. Canções e provérbios sempre falam

\footnotetext{
${ }^{27}$ Estudos de gênero sob a perspectiva feminina. ABBOTT. Jane Austen - a beginner's guide, p. 65.

${ }^{28}$ (gynocriticism) - Esta teoria está focada nos estudos relatives às mulheres escritoras que tentaram mudar o cânone tradicionalmente definido pelos homens. O objetivo é buscar a definição e a distinção entre a escrita feminina e a masculina (ABBOTT. Jane Austen - A Beginner’s Guide, p. 65.)

${ }^{29}$ KIRKHAM. Jane Austen, feminism and fiction.

${ }^{30}$ BOMARITO; HUNTER. Feminism in literature - a gale critical companion.

${ }^{31}$ LOOSER. Jane Austen and discourses of feminism.

${ }^{32}$ MOODY. Marriage and the alternatives: the status of women.

${ }^{33}$ Alguns estudiosos chamam de "protofeminismo".

${ }^{34}$ AUSTEN. Orgulho e preconceito, p. 133. (grifos nossos)

${ }^{35}$ KIRKHAM. Jane Austen, feminism and fiction, p. 102.

${ }^{36}$ MOODY. Feminism in Jane Austen. The Republic of Pemberley,
} 
da volubilidade feminina. Mas talvez me dirá que foram escritos por homens.”37 Por sua vez, Anne Elliot defende as mulheres e responde: “(...) por favor, não faça referência a exemplos de livros. Os homens levaram todas as vantagens sobre nós ao contar sua própria história. (...) A pena esteve em suas mãos. Não posso admitir que os livros provem alguma coisa.”38

Finalmente, em um outro exemplo, em Persuasão, é possível observar outro protesto na conversa entre Anne e o Capitão Harville: “(...) vivemos em casa, tranqüilas, confinadas, e nossos sentimentos nos atormentam (...) (vocês) sempre têm uma profissão, atividades, alguma espécie de negócio para fazê-los voltar imediatamente ao mundo (...).”39

\section{CONCLUSÃO}

Através do rico universo feminino presente nas obras de Jane Austen, é possível vislumbrar o contexto da sociedade do século 19 sob a ótica dos personagens em suas rotinas diárias. Por se tratar de um material vasto, rico em detalhes e informações, este artigo buscou fazer um levantamento das principais características, hábitos e costumes da época retratados na obra da escritora. O conhecimento das regras, leis e normas de etiqueta foi fundamental para o entendimento das atitudes de determinados personagens, além de oferecer uma contextualização dos fatos ocorridos em cada uma das histórias. É importante salientar que, mesmo escrevendo sobre um contexto limitado, (pequenas propriedades rurais ou vilarejos), a escritora pôde descrever um universo de personagens, lugares e situações; tornando seu texto um rico exemplar da sociedade daquele século. Mesmo não fazendo parte do movimento feminista da década de 1960, Jane Austen criticava, de maneira sutil, a situação na qual a mulher de seu tempo se encontrava e era obrigada a viver. Embora não promulgasse mudanças, Austen deixa a critério do leitor o entendimento e a reflexão acerca de temas polêmicos, principalmente para sua época.

\footnotetext{
${ }^{37}$ AUSTEN. Persuasão, p. 278.

${ }^{38}$ AUSTEN. Persuasão, p. 277-278.

${ }^{39}$ AUSTEN. Persuasão, p. 277.
} 


\section{Abstract}

In $19^{\text {th }}$ British society of $19 \mathrm{~h}$ Century, the roles of women were confined to the dedication to their houses or to the search for an advantageous marriage in order to achieve financial security and stability. Jane Austen, however, focuses on the importance of women within the family, on marriage, on social relations and on the role of women in society. This article discusses feminism in Austen's works.

\section{KEYWORDS}

British Society in the 19th century, women in literature, Jane Austen

\section{REFERÊNCIAS}

ABBOTT, Rob. Jane Austen - a beginner's guide. London: Hodder \& Stoughton, 2001.

AUSTEN, Jane. A Abadia de Northanger. Trad. Lêdo Ivo. Rio de Janeiro: Francisco Alves: 1982.

AUSTEN, Jane. Emma. Trad. Ivo Barroso. Rio de Janeiro: Nova Fronteira, 1996a.

AUSTEN, Jane. Persuasão. Trad. Luiza Lobo. Rio de Janeiro: Francisco Alves, 1996b.

AUSTEN, Jane. Emma. New York: Oxford University Press, 2003.

AUSTEN, Jane. Letters of Jane Austen - Letters to her niece Fanny Knight (1814-1816). The Republic of Pemberley, 2004. Disponível <http://www.pemberley.com/janeinfo/brablt15.html\#letter83>. Acesso em: 20 abr. 2011.

AUSTEN, Jane. Sandition and The Watsons - Austen's Unfinished Novels. New York: Dover Publications, 2007.

AUSTEN, Jane. Orgulho e preconceito. Trad. Lúcio Cardoso. São Paulo: Clássicos Abril Coleções, 2010.

BOMARITO, Jessica. HUNTER, Jeffrey W. (Ed.). Feminism in Literature - A Gale Critical Companion. Volume 2 - 19th Century, Topics and authors (A-B). Thomson Gale: Farmington Hills, 2005.

COPELAND, Edward. Money. In: MCMASTER, J.; COPELAND, Edward. The Cambridge Companion to Jane Austen. Cambridge: Cambridge University Press, 1997. p. 131-148.

DOWNING, Sarah J. Fashion in the time of Jane Austen. Oxford: Shire Library, 2010.

JANE AUSTEN'S HOUSE MUSEUM. The Manners and Customs of life in Jane Austen's time - or how to win the mating game. 2010a. Disponível em: <http://www.jane-austenshouse-museum.org.uk/educ_schools/pdfs/Manners_and_Customs.pdf $>$. Acesso em: 20 abr. 2011.

JANE AUSTEN'S HOUSE MUSEUM. The World that Jane Austen Presents. 2010b. Disponível em: $\quad<$ http://www.jane-austens-housemuseum.org.uk/educ_schools/pdfs/Manners_and_Customs.pdf>. Acesso em: 20 abr. 2011. 
KIRKHAM, Margaret. Jane Austen, feminism and fiction. New Jersey: The Athone Press, 1997.

LOOSER, Devoney (Ed.). Jane Austen and discourses of feminism. New York: Palgrave Macmillan, 1995.

MCMASTER, Juliet. Class. In: McMaster, J. Copeland, Edward. The Cambridge Companion to Jane Austen. Cambridge: Cambridge University Press: 1997, p. 115-129.

MOODY, Ellen. Classifications of the Marriages in Jane Austen's Writings. The Republic of Pemberley, 1996. Disponível em: <http://www.pemberley.com/janeinfo/ausmarrg.html>. Acesso em: 20 abr. 2011.

MOODY, Ellen. Feminism in Jane Austen. The Republic of Pemberley, 2004a. Disponível em: <http://www.pemberley.com/janeinfo/pptopic2.html\#protofem1>. Acesso em: 20 abr. 2011.

MOODY, Ellen. Marriage and the alternatives: the status of women. The Republic of Pemberley, 2004b. Disponível em: <http://www.pemberley.com/janeinfo/pptopic2.html\#protofem3>. Acesso em: 20 abr. 2011.

SAINT ANDREW'S UNIVERSITY. Self and Society in the Victorian Novel - Women and the Law in Victorian England. [20?] Disponível em: <http://www.standrews.ac.uk/ www_se/personal/pvm/Women.html>. Acesso em: 20 abr. 2011.

SHEP, R. L. Regency etiquette: the mirror of graces, 1811. Republicado por R. L. Shep: USA, 1997.

SULLIVAN, Margaret C. The Jane Austen Handbook - A Sensible Yet Elegant Guide to Her World. Philadelphia: Quirk Books, 2007.

TERRY, Judith. Seen But Not Heard: Servants in Jane Austen's England. Persuasions, 10th edition, 1988, p. 104-116. Disponível em: <http://www.jasna.org/persuasions/printed/number10/terry.htm>. Acesso em: 20 abr. 2011. 